Dantas Filho, J.B.P., Lima, M.M.X., Heineck L.F.M, Tzortzopoulos, P. and Barros Neto, J.P., 2017. "Waiting

Times in Design Process: a Case Study." In: LC3 2017 Volume II - Proceedings of the 25th Annual

Conference of the International Group for Lean Construction (IGLC), Walsh, K., Sacks, R., Brilakis, I.

(eds.), Heraklion, Greece, pp. 483-489. DOI: https://doi.org/10.24928/2017/0294

\title{
WAITING TIMES IN DESIGN PROCESS: A CASE STUDY
}

\author{
João Bosco P. Dantas Filho ${ }^{1}$, Mariana M. Xavier de Lima ${ }^{2}$, Luiz Fernando M. Heineck ${ }^{3}$, \\ Patricia Tzortzopoulos ${ }^{4}$ and José de Paula Barros Neto ${ }^{5}$
}

\begin{abstract}
This research focuses on identifying waiting time in design process. This comprised the application of value stream mapping to identify existing flows and design waiting times. From this diagnosis, it was possible to propose recommendations reducing identified waste of time. This study demonstrates the viability of using the value stream mapping and to improve architectural designs process.
\end{abstract}

Keywords: Design process, Lean design, wait.

\section{INTRODUCTION}

Poor design management has been identified as an important factor in reducing the construction industry overall performance and efficiency (Love \& Edwards 2004). Poor communication, lack of adequate documentation, lack of information input, unbalanced allocation of resources, lack of coordination between disciplines, and irregular decisionmaking are examples of problems associated with design, for long identified in literature (Koskela et al. 1997).

In order to reduce the problems aforementioned, studies have identified that integration between design and construction processes has become a requirement to improve construction performance. Also, lean design has been described as having potential to better integrate design and construction activities (Jørgensen \& Emmitt 2009).

Lean Design deals with managing the design process complexities, aiming to reduce waste and leverage activities that add value (Rischmoller et al. 2006). Lean Design also incorporates new ways of visualizing design process and this increases understanding of how it works (Freire \& Alarcón 2002). This is due to understanding of design from three perspectives: conversion, flow and value generation (Tzortzopoulos \& Formoso 1999). Given this context, the question that guided this work is: How can architectural design processes be diagnosed in order to become leaner? The objective of this research is to diagnose architectural design processes, taking into account lean design perspective.

Architect, Federal Institute of Education, Science and Technology of Ceará, Researcher of the GERCON, Federal University of Ceará, Fortaleza, Brazil, arquibosco@gmail.com

2 Adjunct Professor, Department of Architecture and Urbanism, Coordinator of the Design Course, Federal University of Ceará, Fortaleza, Brazil, lima.mmxavier@gmail.com

3 Lecturer, State University of Ceará, Fortaleza, Brazil, freitas8@terra.com.br

4 Professor, School of Art, Design and Architecture, Department of Architecture and 3D Design, University of Huddersfield, Huddersfield, UK, p.tzortzopoulos@hud.ac.uk

5 Full Professor, Department of Structural Engineering and Civil Construction, Leader of the GERCON, Federal University of Ceará, Fortaleza, Brazil, barrosneto@gercon.ufc.br 


\section{LITERATURE REVIEW}

\subsection{Architectural Design Process}

This work focuses on design process from a managerial perspective, and it does not include an approach based on the creative process.

The Royal Institute of British Architects (RIBA) promotes its RIBA Plan of Work: an important work reference and guide for better practices for buildings project and construction processes (RIBA 2013). In Brazilian context, many researchers have proposed process models to support architectural design management. Brazilian Association of Architecture Offices (AsBEA) promotes stages and sequencing proposed by Cambiaghi and Amá (2006). These activities are described in Table 1.

Table 1 - Activities performed in order to generate Architecture Design.

\begin{tabular}{ccc}
\hline Activity & Descriptions & Output \\
\hline Product Conception & Conception and feasibility analysis & Preliminary Study \\
Product Definition & Preliminary architectural solution & Legal Design \\
Interface Coordination & Coordination of all designs & Basic Design \\
Detailing & Final Solution and Constructive Detailing. & Executive Design \\
\hline
\end{tabular}

\subsection{Improvement methodology}

The introduction of lean manufacturing concepts in construction sector focuses on alleviating design and construction problems and on propagating decisions and actions efficiency (Emuze \& Saurin 2016).

Lean design is a paradigm by which design process can be done more efficiently and achieving better quality results (Tilley 2005). Lean Design promotes different points of view to model, analyse and understand design process that, under this paradigm, is considered as a group of three distinct models: conversion, flow and value generation (Freire \& Alarcón 2002; Tzortzopoulos \& Formoso 1999). A set of Lean Design practices improved the design process as they minimized waste and maximized efficiency (Lee et al. 2010).

Reducing errors, cycle times, and part of activities without adding value, thus increasing productivity are aims of an improvement methodology proposed by Freire And Alarcón (2002) with following steps: (1) diagnosis and evaluation; (2) Changes implementation; (3) Control; (4) Standardization.

Ko e Chung (2014) analysed design processes in order to make it lean. A new stream was proposed to improve workflow, reduce errors, increase design reliability as design team members receive feedback on each design step performed allowing continuous improvement (Ko \& Chung 2014).

\subsection{Value Stream Map (VSM)}

VSM comprises action mapping to bring a product from raw material to customer (Rother $\&$ Shook 2003). This is a qualitative Lean technique used to analyse and design the flow of materials and information needed to deliver a product, service or design to a consumer. 
VSM focuses on analysing processes time and flow, from the beginning to the end of product development. Drawing current state map by collecting data in the workplace is the first VSM step. The map of the current state will serve as a baseline for drawing a future state map, that should contain ideas and recommendations aimed at improving undesirable situations identified in the current state (O'Connor \& Swain 2013). The final step is to write an implementation plan that describes how to achieve such future state. VSM clearly identifies the real production process situation, indicating the main information flow and time demanded by each activity.

\section{METHOD}

In qualitative methodology adopted facts are observed and described without allowing theoretical preconceptions to alter their nature and importance, besides requiring the study of essential structures connections and relations with the outside (Gil 2008).

In this study, an ex post-facto research is carried out, an investigation in which the manifestation of the variables studied has already occurred and, therefore, is not manipulable (Gil 2008). The research strategy herein was a single case study (Yin 2011).

The case study company has nearly thirty years of experience in architectural design and operates in residential, commercial and public buildings market. The project analysed is a residential building with 46 apartments distributed in twenty-three floors, containing two basements, a ground floor garage, and ballroom and leisure area. The design area corresponds to just a little more than $8.690 \mathrm{~m}^{2}$. The project will be built in Fortaleza Ceará, Northeast of Brazil. The company's sum of characteristics gave basis to the study and the project, to which the studied design refers, evidences that this is a typical case in this context. Thus, the single case study is justified because it is a typical case with commonplace situation of a design firm acting for the real estate market and the lessons learned here are considered informative for many other companies (Yin 2013).

Data collection was carried out through four structured interviews. The participants interviewed were professionals who worked on case study project in the following positions: Architect Director, Architect Coordinator, Architect Collaborator and Architecture trainee. The interview script used was composed of five groups of questions designed to: (1) record participants' profiles; (2) map the value stream; (3) capture the participants' perception regarding time distribution; (4) identify performance indicators; (5) identify waste and opportunities for improvement. Data collection also included documents examining of digital folders and digital design files located in computer servers of the case study company.

The analytical procedures are of qualitative nature, and content analysis was used to analyse the interview data.

The case study protocol designed for this work (figure 1) adopts lean construction tools promoted by the book "Implementing lean in construction: Lean tools and techniques - an introduction" (O'Connor \& Swain 2013). Case study protocol is a particularly effective way of dealing with the problem and increase the case studies reliability (Yin 2013).

\begin{tabular}{|c|ccc|c|}
\hline STEP 1 & STEP 2 & STEP 3 & STEP 4 & STEP 5 \\
\hline $\begin{array}{c}\text { Research } \\
\begin{array}{c}\text { Presentation } \\
\text { and }\end{array}\end{array}$ & $\begin{array}{c}\text { Data collection } \\
\text { Interviews and } \\
\text { documents } \\
\text { Team Commitment }\end{array}$ & $\begin{array}{c}\text { Analysis of } \\
\text { cycle times }\end{array}$ & $\begin{array}{c}\text { Current state } \\
\text { VSM }\end{array}$ & $\begin{array}{c}\text { Future state } \\
\text { VSM }\end{array}$ \\
\hline
\end{tabular}

Figure 1 - Case study protocol 
In step 1, a research presentation was made to the company's Director in order to obtain authorization and commitment from the design team with this research.

In step 2, interviews were conducted with professionals who participated directly in developing design chosen as the case study object. Subsequently, documents examining were conducted in virtual folder containing all design information documents. No copies of files were made because they were confidential information. The researcher had access to the documents to examine them inside the company through visits in office. While in workplace, it was possible to analyse, identify the content, and release date of design documents. The variables that were being evaluated were dates associated with stage of design process which document was related to. Documents examining based the analysis of cycle time. The documentary evidence examined was present in the folder of files loaded or downloaded from the Construmanager ${ }^{6}$. The use of the Construmanager platform by designers left an audit trail for researcher to trace author, action, date and time, of each document, eliminating the existence of different interpretations of "what happened." All the designers' interaction occurred by sharing online design versions in the Construmanager, and this enabled the interactive loops to be incorporated into the data collection. In this work, cycle time is understood as time required to produce a part or complete a process (Shook \& Marchwinski 2014). However, an adaptation was made in the method as the cycle time is calculated. This is justified because it was not possible to calculate the cycle time making a 'real time measurement', since the facts analysed had already occurred. Thus, the sum of days elapsed from documents related to each activity is considered in this work as the activity cycle time activity.

In step 3, it was possible to construct a timeline and calculate the elapsed time between each document with DATES of each design information elaborated by designers. It was possible to perform waiting time identification and visualization of improvement opportunities.

In step 4, the current state VSM was design based on data collected in interviews with participants and on documents examining. Current state VSM shows the real process situation, especially indicating time demanded by each activity and between them.

In step 5, the future state VSM was proposed containing ideas and recommendations aimed at improving undesirable situations identified in current state. This collected and structured information was presented in a new interview with each company participating in research allowing results validation and especially of wastes and proposed improvement opportunities.

\section{RESULTS}

\subsubsection{Analysis of cycle times}

Cycle time analysis demonstrates that Interface Coordination and Detailing are activities with the longest cycle time and exceed the average time (figure 2). It also demonstrates a large amount of waiting time between activities product Conception and Definition.

Product Conception and Product Definition activities have cycle times lower than average time of process activities, but excessive waiting time between them was excessive being almost twice the average of productive activities. Two different types of waiting

\footnotetext{
${ }^{6}$ Construmanager is an online platform for design and construction management in the architecture, engineering and construction sector. It is a solution to have all designs and documents in one place, connect and integrate people and ensure that everyone is always with the latest version of each document.
} 
time were identified: (1) external wait, which occurs when Architects wait for information from other designers e.g. structure and / or MEP; (2) internal wait that occurs when Architects stop working it to complete activities from a different project (work prioritisation within the architectural firm). Long internal waitings such as those from 4 or 13 weeks should be avoided.

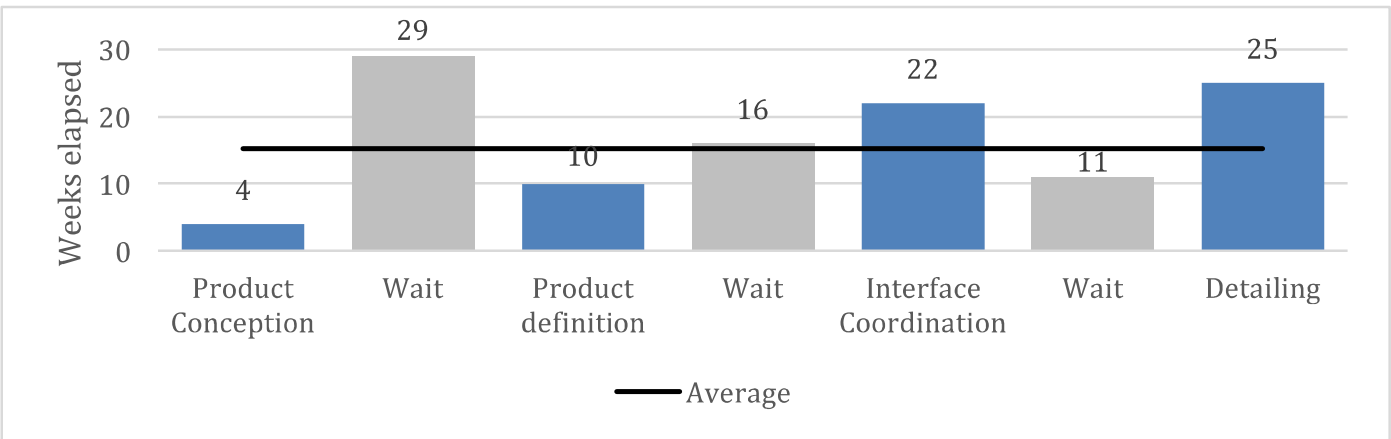

Figure 2 - Distribution of cycle times between design disciplines

\subsection{Current state VSM}

The current state value stream map, shown in figure 3, identifies sequencing activities of architectural process and its interactions with different designs. Out of the total of 124 weeks of design process, 78 weeks were in architectural design and 46 weeks were in external wait, when the project waited for structure and MEP designers.

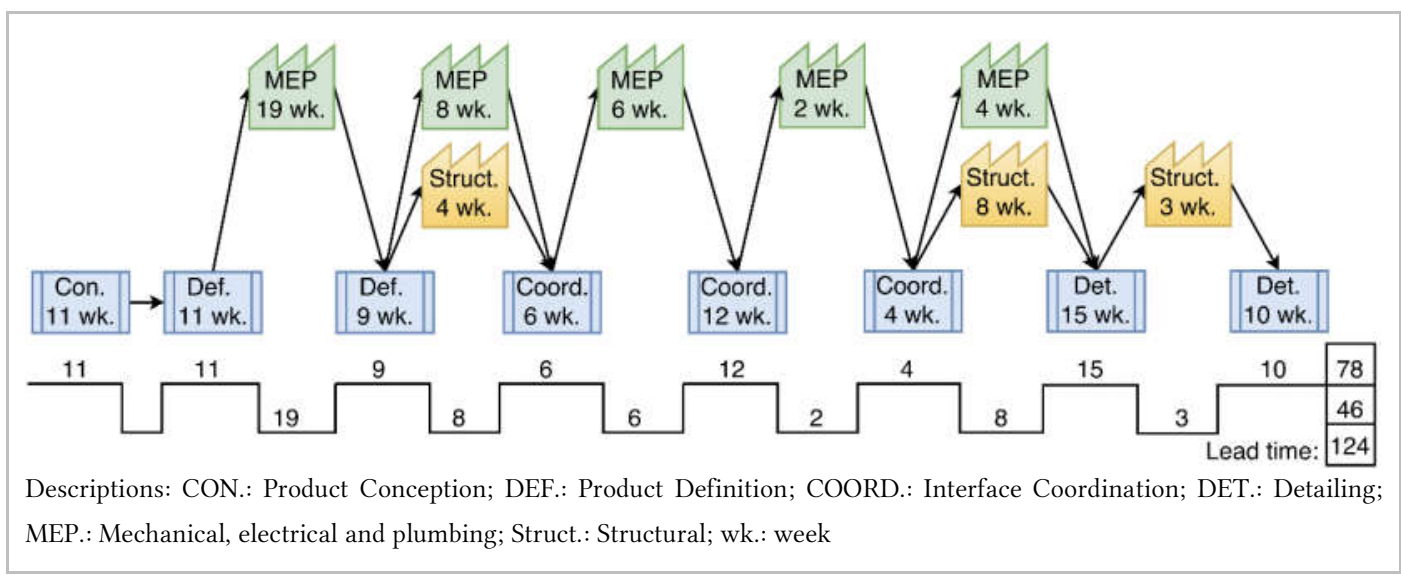

Figure 3 - Current state Value Stream Map of architectural design process

As seen in VSM shown in Figure 3, value flow follows from design conception to definition without any interaction with other designers. Therefore, an initial effort is made to Product Conception. At the end of the Product Conception and after client's approval, the design receives an effort from the Product Definition, and then only after these two steps the architectural design was sent to MEP and structure designers.

Product Definition occurs in two cycles because an interaction is performed with MEP designer. Product Definition is reviewed based on information from this interaction. At this moment, architectural design is sent simultaneously to structure and MEP. There is an interesting relationship with these designs because it allows flow in parallel. The first Interface Coordination is carried out after receipt of structure and MEP designs. Then, two exchanges information cycles are carried out with MEP designer. Again, design is sent 
simultaneously to structure and MEP with modification requests for design compatibility. Then, architectural design goes into Detailing, but an information exchange is needed with structural designer due to omission of some structural information.

In activities of Product Definition, Interface Coordination and Detailing, it was verified that part of cycle time referred to time of value added in development of design and part of time referred to internal waitings that did not have an adequate management and became excessively long.

\subsection{Future state VSM}

Following an analysis of current state VSM there was a clear indication that benefits could be achieved by proposing a future state value map focusing on reducing waiting times, shown in figure 4.

The proposed changes focus essentially on four aspects summarized below: (1) Elaboration of structure and MEP requirements to be used as input to Product Definition stage; (2) Establish a limit of two weeks for internal waits so that architecture office return to work on the design that is in internal wait ; (3) Standardize the sending of architectural design simultaneously to the structure and MEP companies; (4) Interface Coordination made with structure, MEP and architecture designs simultaneously in order to reduce number of process steps.

The new flow makes it possible to reduce process time from 124 to 66 weeks, which is equivalent to a reduction of $47 \%$. Note that steps of structure and MEP designs were not eliminated, but their cycle time was put in parallel because of the sending of architectural design simultaneously to the companies of structure and MEP. As a result, external waiting time is reduced from 46 to 27 weeks, which is equivalent to a reduction of $41 \%$.

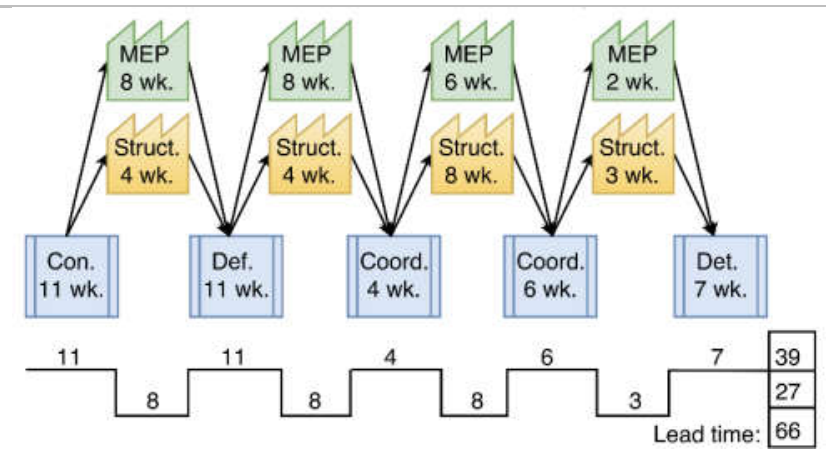

Descriptions: CON.: Product Conception; DEF.: Product Definition; COORD.: Interface Coordination; DET.: Detailing; MEP.: Mechanical, electrical and plumbing; Struct.: Structural; wk.: week

Figure 4 - Proposed Future Value Stream Mapping for architectural design process

\section{CONCLUSIONS}

This work illustrated the design process complexity through structuring and identification of waiting time in design process of an architectural company case study.

It was demonstrated through study that mapping and analysing value stream are viable tools for improving architectural design process. Designers can get improvements by applying these tools to their design processes. The data collected in case study illustrate that $50 \%$ of time of architectural design process is time without value aggregation and directly impact total time. 
João Bosco P. Dantas Filho, Mariana M. Xavier de Lima, Luiz Fernando M. Heineck, Patricia Tzortzopoulos and José de Paula Barros Neto

The main contributions of this work was the waiting times exposure in design process, proposing improvement opportunities for companies based on real problems identified, and structuring of methodology for application of lean diagnostic tools in context of architectural design offices.

Finally, a research restriction is that proposed modifications have not been implemented in design companies. However, the findings from this case study provide important insights that allow recommendations to be made for future successful implementations.

\section{REFERENCES}

Cambiaghi, H. \& Amá, R., 2006. Manual de Escopo de Projetos e Serviços de Arquitetura e Urbanismo. São Paulo: AsBEA.

Emuze, F.A. \& Saurin, T.A., 2016. Value and Waste in Lean Construction, Routledge.

Freire, J. \& Alarcón, L.F., 2002. Achieving lean design process: Improvement methodology. Journal of Construction Engineering and management, 128(3), pp.248-256.

Gil, A.C., 2008. Métodos e técnicas de pesquisa social 6a Edição., São Paulo: Atlas.

Jørgensen, B. \& Emmitt, S., 2009. Investigating the integration of design and construction from a "lean" perspective. Construction Innovation, 9(2), pp.225-240.

Ko, C.-H. \& Chung, N.-F., 2014. Making Design Process Lean. In IGLC 22. pp. 463-474.

Koskela, L., Ballard, G. \& Tanhuanpää, V.-P., 1997. Towards Lean Design Management. In S. N. Tucker, ed. 5th Annual Conference of the International Group for Lean Construction. Senior Researcher, VTT Building Technology, Espoo, Finland. Available at: http://iglc.net/Papers/Details/27/pdf.

Lee, H.W., Tommelein, I.D. \& Ballard, G., 2010. Lean design management in an infrastructure design-build project: A case study. In IGLC 18. pp. 113-122.

Love, P.E.D. \& Edwards, D.J., 2004. Determinants of rework in building construction projects. Engineering, Construction and Architectural Management, 11(4), pp.259-274.

O'Connor, R. \& Swain, B., 2013. Implementing lean in construction: Lean tools and techniques- an introduction., London: CIRIA. Available at: http://goo.gl/omnN0W.

RIBA, 2013. RIBA plan of work 2013 overview D. Sinclair, ed., London: Royal Institute of British Architects. Available at: www.ribaplanofwork.com.

Rischmoller, L., Alarcón, L.F. \& Koskela, L., 2006. Improving value generation in the design process of industrial projects using CAVT. Journal of management in engineering, 22(2), pp.52-60.

Rother, M. \& Shook, J., 2003. Learning to See Value Stream Mapping to Create Value and Eliminate Muda. Lean Enterprise Institute Brookline, p.102.

Shook, J. \& Marchwinski, C., 2014. Lean lexicon: A graphical glossary for lean thinkers, Lean Enterprise Institute.

Tilley, P.A., 2005. Lean Design Management: A New Paradigm for Managing the Design and Documentation Process to Improve Quality? In 13th International Group for Lean Construction Conference: Proceedings. International Group on Lean Construction, p. 283.

Tzortzopoulos, P. \& Formoso, C., 1999. Considerations on application of lean construction principles to design management. Proceedings IGLC, 7, pp.26-28.

Yin, R.K., 2013. Case study research: design and methods, SAGE Publications, Inc.

Yin, R.K., 2011. Qualitative Research From Start To Finish, New York: The Guilford Press. 